\title{
Expression of selected genes of dendritic and Treg cells in blood and skin of morphea patients treated with UVA1 phototherapy
}

\author{
Agnieszka J. Osmola-Mańkowska1 ${ }^{1}$ Ewa Teresiak-Mikołajczak', Michał J. Kowalczyk², \\ Ryszard W. Żaba², Zygmunt Adamski³, Aleksandra Dańczak-Pazdrowska
}

\begin{abstract}
${ }^{1}$ Psoriasis and Novel Therapies Unit, Department of Dermatology, Poznan University of Medical Sciences, Poznan, Poland

2Department of Dermatology and Venereology, Poznan University of Medical Sciences, Poznan, Poland

${ }^{3}$ Department of Dermatology, Poznan University of Medical Sciences, Poznan, Poland
\end{abstract}

Submitted: 22 August 2015

Accepted: 19 October 2015

Arch Med Sci 2018; 14, 2: 361-369

DOI: https://doi.org/10.5114/aoms.2018.73469

Copyright @ 2018 Termedia \& Banach

\begin{abstract}
Introduction: Morphea is a chronic autoimmune disease characterized by fibrosis of the skin. Dendritic cells (DC) and regulatory T cells (Tregs) play a significant role in development of autoimmune and tolerance mechanisms. The aim of the study was to establish the expression of selected genes of plasmacytoid and myeloid DC, Treg cells, and the microenvironment of cytokines (interleukin-17A (IL-17A), transforming growth factor $\beta$ (TGF- $\beta$ )) in blood and skin of morphea patients. In addition, the effect of UVA1 phototherapy on expression of the aforementioned genes was evaluated.

Material and methods: The study was performed on 15 blood and 10 skin samples from patients with morphea. The evaluation included expression of CLEC4C (C-type lectin domain family 4, member $C$ receptor), Lymphocyte antigen 75 (LY75), Forkhead box p3 (foxp3) transcription factor, IL-17A and TGF- $\beta$ genes in peripheral blood mononuclear cells (PBMC) and in skin samples both before and after UVA1 phototherapy using real-time polymerase chain reaction. Results: The study revealed lower expression of CLEC4C before $(p=0.010)$ and after $(p=0.009)$ phototherapy and lower expression of IL-17A before $(p=0.038)$ phototherapy in PBMC of patients with morphea vs. the control group. Expression of CLEC4C in PBMC correlated negatively (rho $=-0.90$; $p=0.001$ ) with activity of disease after phototherapy. No significant differences were found between expression of analysed genes before and after UVA1 therapy in PBMC and skin of morphea patients.

Conclusions: The results do not confirm the involvement of analysed subsets of DC and Tregs in UVA1 phototherapy in morphea, but point to CLEC4C as a possible biomarker associated with the disease activity.
\end{abstract}

Key words: regulatory $T$ cells, plasmacytoid dendritic cells, myeloid dendritic cells.

\section{Introduction}

Localized scleroderma (morphea) is an autoimmune disease characterized by fibrosis of the skin and underlying tissues [1]. Studies performed on animal models and in vitro on factors involved in activation of certain dendritic cell (DC) populations in autoimmune diseases point

\author{
Corresponding author: \\ Ewa Teresiak-Mikołajczak \\ Department of Dermatology \\ Poznan University \\ of Medical Sciences \\ 49 Przybyszewskiego St \\ 60-355 Poznan, Poland \\ Phone: +48 601957851 \\ E-mail: ewa.teresiak@wp.pl
}


to a significant role of recently discovered lectin receptors such as C-type lectin domain family 4, member $C$ receptor (CLEC4C) and lymphocyte antigen 75 (LY75) [2, 3]. CLEC4C or cluster of differentiation 303 (CD303), also known as blood dendritic cell antigen (BDCA-2), is a type II C-type lectin specifically expressed by human plasmacytoid DC (pDC) and plays a significant role in activation of $\mathrm{pDC}$ and in development of antigen-specific T lymphocytes [3, 4]. In turn, LY75 or CD205 receptor, also known as DEC205 (the dendritic cell receptor for endocytosis), participates in recognition and trapping of autoantigens released during apoptosis or cell necrosis [5]. Expression of LY75 receptor is typical for myeloid $\mathrm{DC}(\mathrm{mDC})$, the presence of which is noted in non-lymphoid peripheral tissues, such as in the skin. It is suggested that $\mathrm{mDC}$ play a significant role in maintenance of tolerance to own antigens but so far no investigations have been performed on their involvement in pathogenesis of morphea [5]. According to some authors, ingestion of apoptotic bodies by DC manifesting CD205+ phenotype initiates production of transforming growth factor $\beta$ (TGF- $\beta$ ) by the cells, which promotes differentiation of Tregs [2].

Regulatory $T$ cells can inhibit the function of other $T$ cells and thus promote the maintenance of self-tolerance mechanisms. One of the most specific markers of Tregs is the Forkhead box p3 (foxp3) transcription factor [5]. Significance of the molecule was confirmed in studies on mouse models of foxp3(-) burdened with a defect of Tregs and with a severe lymphoproliferative autoimmune syndrome.

The significance of interleukin-17A (IL-17A) has been postulated recently in several autoimmune diseases, including systemic sclerosis (SSc) $[6,7]$. IL-17A increases the production of cytokines enhancing the tissue remodelling process, affects apoptosis of endothelial cells and promotes proliferation and differentiation of $B$ lymphocytes into plasma cells $[6,7]$.

To our knowledge, no one has previously studied the potential effects of UVA1 phototherapy on number of Tregs, pDC and $\mathrm{mDC}$ in skin and/ or blood of morphea patients. Demonstration of such effects would be consistent with clinical observations of excellent results of such therapy. UVA1 phototherapy affects various stages of the pathomechanism of morphea. It inhibits the inflammatory process, preventing progress of the disease, and affects fibrosis, resulting from inflammation. It also includes immunomodulating function through its ability to induce apoptosis of $\mathrm{T}$ and $\mathrm{B}$ lymphocytes (including the unique phenomenon of early apoptosis, not noted following UVB irradiation), to produce pro-inflammatory cytokines and the ability to induce production of collagenase by fibroblasts [8].
The main purpose of this study was to establish the expression of selected genes characteristic for subpopulations of DC (CLEC4C, LY75) and Treg cells (foxp3), and the microenvironment of cytokines (IL-17A, TGF- $\beta$ ) in blood and skin of morphea patients compared to healthy controls by the real-time polymerase chain reaction (PCR) method. Then the correlations between clinical severity and expressions of aforementioned genes were assessed. Finally the effect of medium dose UVA1 phototherapy on expression of the aforementioned genes after the course of treatment was evaluated.

\section{Material and methods}

The study group included 15 adults suffering from morphea diagnosed and treated in the Dermatology Department. The diagnosis was confirmed by histopathologic examination. Patients presented severe and disseminated forms of morphea and were qualified for phototherapy treatment [8].

The material consisted of 15 (9 ml) blood samples and $10(4 \mathrm{~mm})$ punch skin biopsies obtained before and after the course of treatment with a medium dose of UVA1 phototherapy. The place of the biopsy was the inflammatory margin of sclerotic lesions. The control group included 18 blood samples obtained from blood donors matched according to sex and age and 15 skin biopsies from skin residues after flap reconstruction surgery. All subjects provided written informed consent and the Poznan University of Medical Sciences Bioethics Committee approved the study (Permit Number $651 / 12$ on $14^{\text {th }}$ June 2012 ).

\section{Patients' assessment}

Clinical severity was established before and after the phototherapy according to the localized scleroderma skin severity index (LoSSI), the only validated scale, proposed by the Localized Scleroderma Clinical and Ultrasound Study Group (LOCUS), which together with the localized scleroderma skin damage index (LoSDI) and physician's Global Assessment (PGA) form the Localized Scleroderma Cutaneous Assessment Tool (LoSCAT) [9].

\section{Antinuclear antibodies}

The titre and fluorescent pattern of antinuclear antibodies (ANA) were evaluated using the indirect immunofluorescence method on HEp-2 cells and Ana Profil3 (Euroimmun, Medizinische Labordiagnostika AG) before and after UVA1 phototherapy.

\section{UVA1 phototherapy}

The UVA1 phototherapy was performed using a UVA1 irradiation device (GP-24H, Cosmed- 
ico, Medical Systems, Germany), equipped with 24 high-pressure fluorescent lamps that emit radiation within UVA1 $(350-400 \mathrm{~nm})$ with intensity of $115 \mathrm{~mW} / \mathrm{cm}^{2}$. The medium doses of UVA1 (MD UVA1) were used (the average dose was $45.91 \mathrm{~J} / \mathrm{cm}^{2}$; the average number of irradiations was 31.92, the average number of total doses 1457.69) in a 3-5 times a week scheme. After the treatment was completed, the patients were monitored in the Outpatient Clinic.

\section{RNA isolation}

EDTA-collected blood samples were spun down in Ficoll gradient. Mononuclear cells were aspired and washed in phosphate-buffered saline. Total cellular RNA was extracted using Tri Reagent (MRC, USA) [10]. Following phenol-chloroform extraction the transparent upper-phase samples were further purified using a High Pure RNA Isolation Kit (Roche Diagnostics); however, the genomic DNA was removed in a separate reaction. $1.5 \mu \mathrm{g}$ of RNA was used for a DNase I reaction - DNA-free Kit (Ambion).

The skin biopsies were immediately frozen in liquid nitrogen upon collection. They were stored at $-80^{\circ} \mathrm{C}$ for further processing. The frozen samples were homogenized by a PRO200 rotor-stator homogenizer (Pro Scientific) with Tri Reagent as the medium and frozen again at $-20^{\circ} \mathrm{C}$. Following the phenol-chloroform extraction the transparent upper-phase samples were further purified and DNased using a NucleoSpin RNA XS kit (Macherey-Nagel).

RNA concentration of all samples was measured with a Qubit fluorometer (Invitrogen).
The RNA quality of all samples was assessed by running a no-reverse-transcription negative real-time PCR with glyceraldehyde-3-phosphate dehydrogenase (GAPD) as the target sequence $[11,12]$.

\section{Reverse-transcription and real-time PCR}

$1.0 \mu \mathrm{g}$ of purified RNA was used in the reverse transcription reaction with random hexamer primers using a Transcriptor First Strand cDNA Synthesis Kit (Roche Diagnostics). Aliquots of cDNA were stored at $-80^{\circ} \mathrm{C}$.

Real-time PCR was performed in absolute analysis mode with dilution standard curves. The expression levels were normalized to the geometric mean of the copy number of two reference genes: ACTB ( $\beta$-actin) and GAPD. The expression levels were expressed as copies of the gene of interest per million of the geometric mean of ACTB and GAPD. All reactions were performed on a LightCycler 2.0 thermocycler using a LightCycler FastStart DNA Master SYBR Green I kit (Roche Diagnostics), apart from the GAPD reaction, which was carried out using a LightCycler TaqMan Master kit (Roche Diagnostics). All real-time PCR baths contained a no-template negative control and were cross-calibrated. The product quality was checked using melting point analysis [13]. The primer sequences are presented in Table I.

\section{Statistical analysis}

Non-parametric tests were used for the statistical analysis: the Wilcoxon signed-rank test for the

Table I. Real-time PCR primers of selected genes and references

\begin{tabular}{|c|c|c|c|c|}
\hline Primer & Sequence 5'-3' & $\begin{array}{l}\text { cDNA amplicon } \\
\text { size [bp] }\end{array}$ & $\begin{array}{l}\text { Estimated genomic } \\
\text { amplicon size [bp] }\end{array}$ & Reference data \\
\hline IL-17A-F & CTCATTGGTGTCACTGCTACTG & \multirow[t]{2}{*}{78} & \multirow[t]{2}{*}{1222} & NM_002190.2, \\
\hline IL-17A-R & CCTGGATTTCGTGGGATTGTG & & & RTPrimerDB ID: $7754[11,12]$ \\
\hline TGF- $\beta-F$ & GTGACAGCAGGGATAACACACTG & \multirow[t]{2}{*}{81} & \multirow[t]{2}{*}{220} & \multirow{2}{*}{$\begin{array}{c}\text { ENSTO0000221930 } \\
\text { RTPrimerDB ID: } 1005[12,13]\end{array}$} \\
\hline TGF- $\beta-R$ & CATGAATGGTGGCCAGGTC & & & \\
\hline BDCA-2-F & CTGGGATGCAATCTTGGACT & \multirow{2}{*}{144} & \multirow{2}{*}{6660} & \multirow[t]{2}{*}{ ENSG00000198178 } \\
\hline BDCA-2-R & GATCTGACAGCCCCAGAAAA & & & \\
\hline FoxP3-F & TTCTGTCAGTCCACTTCACCA & \multirow[t]{2}{*}{149} & \multirow[t]{2}{*}{6282} & \multirow[t]{2}{*}{ ENSG00000049768 } \\
\hline FoxP3-R & AGGTCTGAGGCTTTGGGTG & & & \\
\hline Ly75-F & TGGCTTCATGGGTCATGTTA & \multirow[t]{2}{*}{100} & \multirow[t]{2}{*}{11849} & \multirow{2}{*}{$\begin{array}{c}\text { NM_002349, } \\
\text { ENSTO0000263636 }\end{array}$} \\
\hline Ly75-R & GGTCTTCCTGCTCTCCAATG & & & \\
\hline GAPD-F & - & \multirow[t]{2}{*}{119} & \multirow[t]{2}{*}{-} & \multirow{2}{*}{$\begin{array}{l}\text { Human GAPD Gene Assay - } \\
\text { Universal Probe Library } \\
\text { (Roche Applied Science) }\end{array}$} \\
\hline GAPD-R & - & & & \\
\hline ACTB & GCACAGAGCCTCGCCTT & \multirow[t]{2}{*}{93} & \multirow[t]{2}{*}{953} & \multirow{2}{*}{$\begin{array}{l}\text { ENST00000331789, } \\
\text { NM_001101.3 [14] }\end{array}$} \\
\hline ACTB & GTTGTCGACGACGAGCG & & & \\
\hline
\end{tabular}


Table II. Characteristics of the study group (morphea patients)

\begin{tabular}{|c|c|c|c|c|c|c|c|c|}
\hline $\begin{array}{l}\text { No. of } \\
\text { patients }\end{array}$ & $\begin{array}{c}\text { Mean age } \\
\text { [years] }\end{array}$ & Sex & $\begin{array}{l}\text { History } \\
\text { [years] }\end{array}$ & $\begin{array}{c}\text { Morphea } \\
\text { type }\end{array}$ & ANA & ENA & LoSSI & LoSDI \\
\hline 15 & 48 & $\begin{array}{c}12 \text { females } \\
80 \% \\
3 \text { males } \\
20 \%\end{array}$ & 5 & $\begin{array}{c}13 \\
\text { generalized } \\
\text { morphea } \\
(\mathrm{GM}) \\
(87 \%) \\
\\
2 \\
\text { linear } \\
\text { morphea (LM) } \\
(13 \%)\end{array}$ & $\begin{array}{c}13 \\
\text { positive } \\
(87 \%) \\
\\
\text { Titre range: } \\
1: 80- \\
1: 1280 \\
\\
\text { Pattern: } \\
11 \\
\text { granular } \\
(84 \%) \\
\\
2 \\
\text { granular- } \\
\text { speckled } \\
\text { (15\%) }\end{array}$ & $\begin{array}{c}4 \text { positive } \\
(27 \%) \\
\text { Type: } \\
\text { PCNA, Ro52, } \\
\text { AMA M2, } \\
\text { ribosomal } \\
\text { P protein }\end{array}$ & $\begin{array}{l}\text { Before } \\
\text { UVA1 } \\
23.89 \\
\\
\text { After } \\
5.33\end{array}$ & $\begin{array}{l}\text { Before } \\
\text { UVA1 } \\
24.89 \\
\\
\text { After } \\
16.44\end{array}$ \\
\hline
\end{tabular}

ANA - antinuclear antibody, ENA - extractable nuclear antigens, PCNA - proliferating cell nuclear antigen, AMA M2 - antimitochondrial antibodies.

before-after analysis, and Kruskal-Wallis one-way analysis of variance as well as the Spearman correlations test. The statistical significance level was established as $p<0.05$. The calculations were performed by means of the CSS Statistica software.

\section{Results}

The study included 15 morphea patients (mean age: $48 \pm 18$ years; 12 women, 3 men). The exact analysis of the study group is presented in Table II.

All patients completed the treatment cycle and improved after the UVA1 phototherapy. LoSSI (median before 18; median after 5 ) as well as LoSDI scales (median before 26; median after 15) decreased significantly $(p=0.007)$. However, hyperpigmentation observed after the phototherapy influenced the final LoSDI result (Figures 1, 2).

Expression of analysed genes in PBMC and skin in the study group and control group are presented in Tables III and IV, respectively.

The study revealed statistically significantly lower expression of the CLEC4C gene in PBMC



Figure 1. LoSSI scores before and after UVA1 treatment in the group of morphea patients of patients with morphea both before and after UVA1 therapy, as compared to the control group ( $p=0.010$ and $p=0.009$ respectively). The results demonstrated statistically significantly lower expression of the IL-17A gene in PBMC of morphea patients before phototherapy compared to healthy controls $(p=0.038)$ (Figures $3 \mathrm{~A}, \mathrm{~B})$.

The expression of analysed genes in skin samples of morphea patients manifested no significant differences both before and after phototherapy as compared to the control group. Similarly, no significant differences were found when comparing the expression of analysed genes both in PBMC and skin samples of patients with morphea before and after UVA1 therapy.

A positive correlation was noted between expression of foxP3 in skin samples and ANA titre in morphea patients ( $r$ o $=0.89, p=0.006$ ) after phototherapy (Figure 4). On the other hand, a negative correlation was detected between the activity of the disease (measured with LoSSI) and the expression of CLEC4C in PBMC in the study

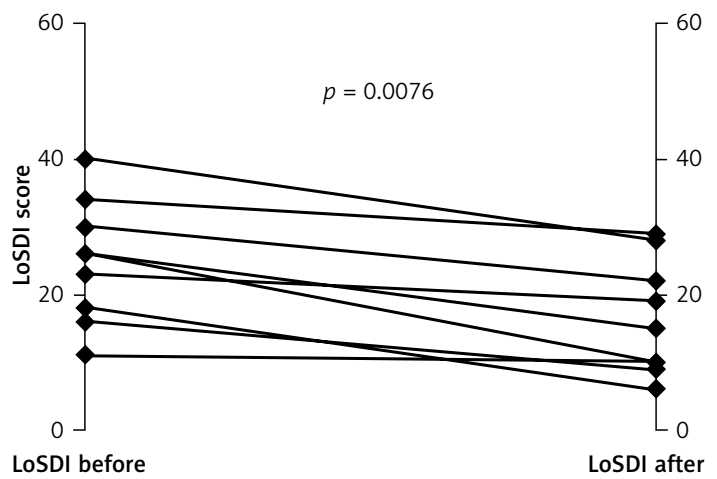

Figure 2. LoSDI scores before and after UVA1 treatment in the group of morphea patients 
Table III. Expression of analysed genes in PBMC in study group and control group. Results are expressed as number of copies per million of the geometric mean of two reference genes (ACTB and GAPD)

\begin{tabular}{|c|c|c|c|c|}
\hline \multirow[t]{2}{*}{ Variables } & & \multicolumn{2}{|c|}{ Morphea $(n=15)$} & \multirow[t]{2}{*}{ Control $(n=18)$} \\
\hline & & Before UVA1 & After UVA1 & \\
\hline \multirow[t]{4}{*}{ FoxP3 } & Min & 2.7 & 25.0 & 114.3 \\
\hline & Max & 1278.8 & 989.7 & 1077.7 \\
\hline & Median & 220.5 & 215.0 & 294.0 \\
\hline & $P$-value & 0.616 & 1.000 & - \\
\hline \multirow[t]{4}{*}{ CLEC4C } & Min & 299.2 & 786.4 & 1440.2 \\
\hline & Max & 4241.5 & 2684.6 & 6368.6 \\
\hline & Median & 1180.8 & 1188.0 & 2530.4 \\
\hline & $P$-value & $0.010^{*}$ & $0.009^{*}$ & - \\
\hline \multirow[t]{4}{*}{ LY75 } & Min & 8132.5 & 16300.8 & 19610.2 \\
\hline & Max & 39785.8 & 60202.0 & 35326.9 \\
\hline & Median & 26411.9 & 27737.7 & 26127.4 \\
\hline & $P$-value & 1.000 & 1.000 & - \\
\hline \multirow[t]{4}{*}{ IL-17 } & Min & 60.9 & 55.6 & 203.5 \\
\hline & Max & 383.4 & 812.7 & 468.3 \\
\hline & Median & 238.3 & 219.6 & 322.3 \\
\hline & $P$-value & $0.038^{*}$ & 0.170 & - \\
\hline \multirow[t]{4}{*}{ TGF- $\beta$} & Min & 54352.4 & 64902.6 & 66867.5 \\
\hline & $\operatorname{Max}$ & 160008.2 & 249838.4 & 135962.0 \\
\hline & Median & 87661.8 & 94708.4 & 95938.8 \\
\hline & $P$-value & 1.000 & 1.000 & 1.000 \\
\hline
\end{tabular}

$P$-value is in comparison to the control group.

Table IV. Expression of analysed genes in the skin in study group and control group. Results are expressed as number of copies per million of the geometric mean of two reference genes (ACTB and GAPD)

\begin{tabular}{|c|c|c|c|c|}
\hline \multirow[t]{2}{*}{ Variables } & & \multicolumn{2}{|c|}{ Morphea $(n=10)$} & \multirow[t]{2}{*}{ Control $(n=15)$} \\
\hline & & Before UVA1 & After UVA1 & \\
\hline \multirow[t]{4}{*}{ FoxP3 } & Min & 8.7 & 109.3 & 56.3 \\
\hline & Max & 1416.8 & 411.1 & 380.4 \\
\hline & Median & 159.5 & 154.9 & 134.0 \\
\hline & $P$-value & 1.000 & 1.000 & - \\
\hline \multirow[t]{4}{*}{ CLEC4C } & Min & 10.3 & 0.000 & 0.000 \\
\hline & Max & 4182.5 & 2676.5 & 941.4 \\
\hline & Median & 161.4 & 271.3 & 45.2 \\
\hline & $P$-value & 0.813 & 0.488 & - \\
\hline \multirow[t]{4}{*}{ LY75 } & Min & 15235.6 & 31787.2 & 28769.1 \\
\hline & Max & 96759.8 & 85600.6 & 82289.6 \\
\hline & Median & 37314.2 & 48226.8 & 52193.1 \\
\hline & $P$-value & 0.965 & 1.000 & - \\
\hline \multirow[t]{4}{*}{ TGF- $\beta$} & Min & 73279.2 & 59799.8 & 41221.7 \\
\hline & Max & 318749.6 & 196113.6 & 1300783.1 \\
\hline & Median & 115026.3 & 120920.6 & 136768.7 \\
\hline & $P$-value & 1.000 & 1.000 & - \\
\hline
\end{tabular}

$P$-value is in comparison to the control group. 
A

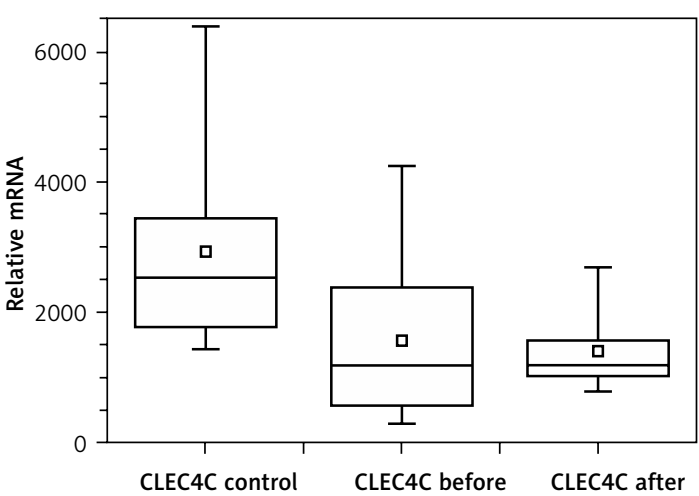

B

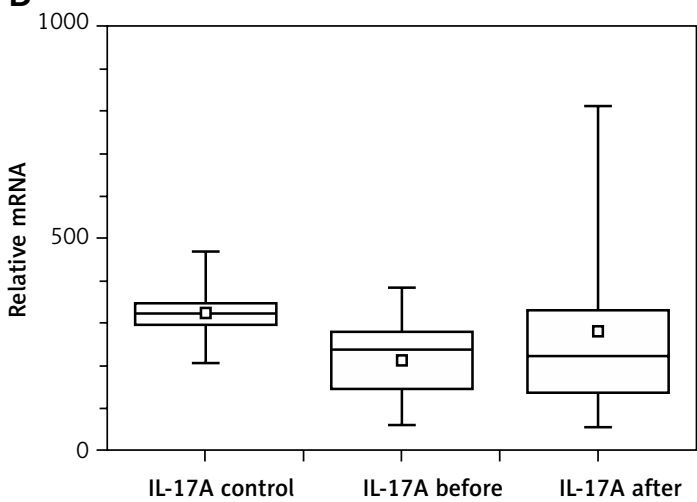

Figure 3. Expression of CLEC4C (A) and IL-17A (B) gene in PBMC in morphea patients. Expression levels are expressed as copies of gene of interest per million of the geometric mean of ACTB copies and GAPD copies

group after phototherapy (rho $=-0.90, p=0.001$ ) (Figure 5). No such relationship was observed before the UVA1 treatment. Moreover, patients with morphea demonstrated a positive correlation between expression of IL-17A and TGF- $\beta$ in PBMC after completing the treatment cycle (rho $=0.79$,



Figure 4. Correlation between ANA titre and foxP3 expression in skin samples after phototherapy. Expression levels are expressed as copies of gene of interest per million of the geometric mean of ACTB copies and GAPD copies

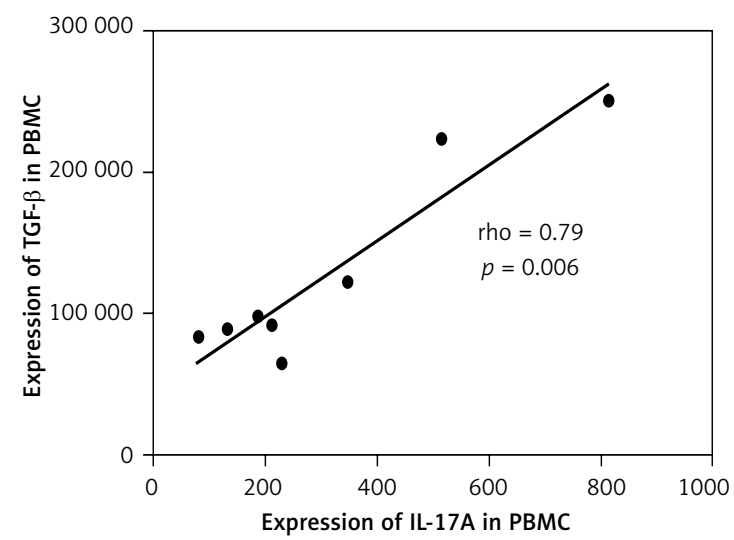

Figure 6. Correlation between expression of IL-17A and expression of TGF- $\beta$ in PBMC after phototherapy. Expression levels are expressed as copies of gene of interest per million of the geometric mean of ACTB copies and GAPD copies $p=0.006)$ (Figure 6). Before the UVA1 treatment a positive correlation was detected between the expression of LY75 and foxP3 in skin samples of morphea patients (rho $=0.78, p=0.008$ ) (Figure 7). The expression of LY75 in skin samples also correlated with the expression of CLEC4C in PBMC

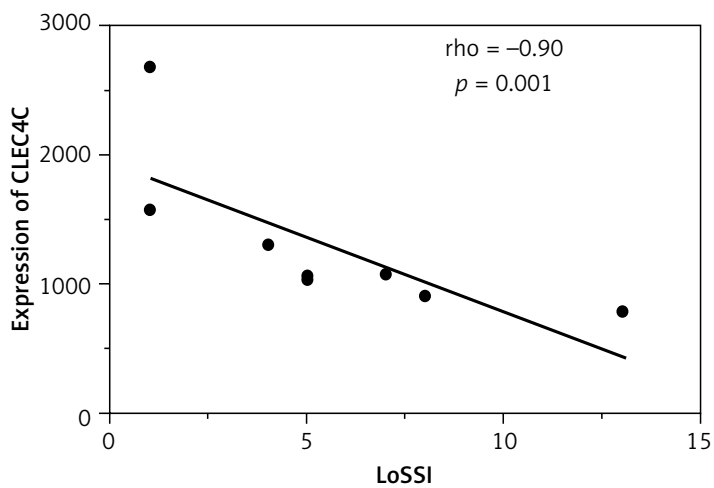

Figure 5. Correlation between LoSSI and the expression of CLEC4C in PBMC after phototherapy. Expression levels are expressed as copies of gene of interest per million of the geometric mean of ACTB copies and GAPD copies



Figure 7. Correlation between expression of Ly75 in the skin and the expression of foxP3 in the skin before phototherapy. Expression levels are expressed as copies of gene of interest per million of the geometric mean of ACTB copies and GAPD copies 


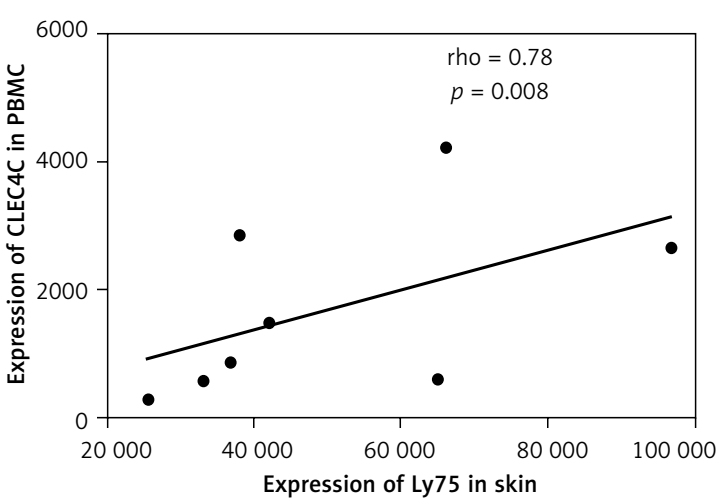

Figure 8. Correlation between expression of Ly75 in skin and expression of CLEC4C in PBMC before phototherapy. Expression levels are expressed as copies of gene of interest per million of the geometric mean of ACTB copies and GAPD copies

of the study group before the treatment (rho = $0.78, p=0.008$ ) (Figure 8). A negative correlation was observed before the treatment between the expression of foxP3 in skin samples and TGF- $\beta$ in PBMC of morphea patients (rho $=-0.77, p=$ 0.009) (Figure 9).

\section{Discussion}

Alterations in the number and function of pDC and $\mathrm{mDC}$ have been implicated in several autoimmune diseases [4]. Wollenberg et al. observed that pDC were as frequent in lesional skin in psoriasis and systemic lupus erythematosus (SLE) as in peripheral blood of healthy people, whereas they were reduced or absent in normal skin [4, 14]. Individual investigations on morphea patients demonstrated a high number of pDC within deeper dermal layers, around blood vessels and in subcutaneous tissue, as well as a decreased population of dermal DC manifesting expression of CD34 $[10,15]$. In our study, lower expression of CLEC4C was observed in PBMC of morphea patients than in healthy controls. This is in agreement with previous studies concerning SLE patients [16]. On the other hand, our results revealed no significant differences in the expression of CLEC4C in the skin of patients with morphea as compared to the control group. Farkas et al. used immunofluorescence staining and demonstrated that pDC accumulate in cutaneous discoid lupus erythematosus (DLE) and SLE lesions, but not in normal skin, and it might be the reason for their decreased number in peripheral blood [17]. The conflicting findings of aforementioned studies may result from different methods used to assess the changes in the amounts of DC subsets in the skin of morphea patients. It is difficult to explain the lack of change in expression of CLEC4C both in PBMC and skin of morphea patients after the UVA1 treatment when the severity of the disease was diminished. The

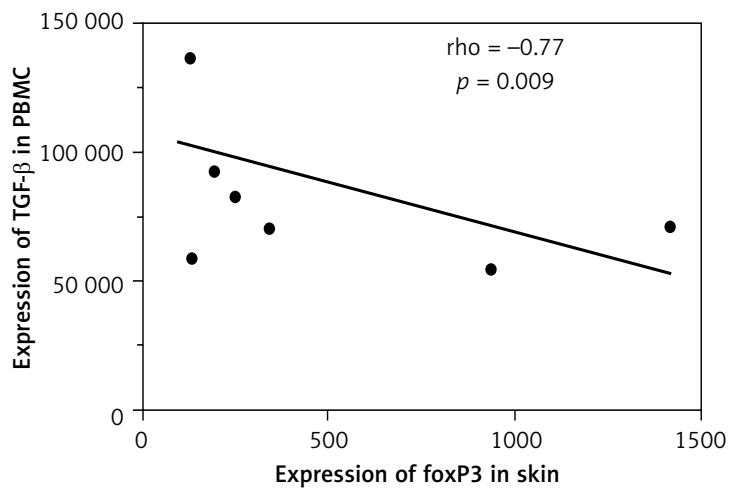

Figure 9. Correlation between expression of foxP3 in skin and TGF- $\beta$ in PBMC before phototherapy. Expression levels are expressed as copies of gene of interest per million of the geometric mean of ACTB copies and GAPD copies

reason for this observation could be the fact that we treat only symptoms of the disease but not the cause of it. In this case one of the complications after discontinuance of UVA1 treatment could be the rebound effect. However, the follow-up observations of the morphea patients treated with UVA1 do not confirm such a phenomenon. In our opinion the most likely explanation is the small size of the study group. Therefore further studies on larger numbers of patients with morphea are necessary.

Until now, just a few studies have demonstrated a decrease in the number and activity of Tregs in patients with SSc and only a single study was related to morphea $[18,19]$. Antiga et al. demonstrated a significantly decreased number of Tregs in blood and dermis of patients with SSc or morphea as well as decreased levels of IL-10 and TGF- $\beta$ in serum $[18,19]$. Another group of investigators in studies on patients with SSc observed no differences in the number of Tregs in peripheral blood but detected an evident decrease in Tregs within skin with typical scleroma lesions [20]. The results of the study failed to reveal increased expression of foxp3 in both lesional skin and PBMC of morphea patients. Similarly, we were not able to confirm differences in expression of TGF- $\beta$ in both lesional skin and PBMC of the patients with morphea, as compared to healthy controls. However, a negative correlation was noted between expression of foxp3 in lesional skin and TGF- $\beta$ in PBMC of morphea patients.

Dendritic cells and Tregs cooperate during the immune response through their direct contact or with mediation of cytokines. Capture of apoptotic bodies by mDC enhances production of TGF- $\beta$. The accompanying increase in TGF- $\beta$ affects differentiation of Foxp3 Treg [2, 5].

Our studies revealed a positive correlation between the expression of LY75 and foxp3 in lesional skin in patients with morphea. Similarly, 
a positive correlation was demonstrated between the expression of LY75 in the skin and CLEC4C in PBMC of morphea patients. Lymphocyte antigen 75 receptor expression is characteristic for $\mathrm{mDC}$. It is suggested that mDC play an important role in the maintenance of tolerance to self-antigens, but so far no studies have shown their participation in the pathogenesis of morphea. According to some authors, uptake of apoptotic bodies by $\mathrm{mDC}$ initiates TGF- $\beta$ production by these cells, which promotes the differentiation of Tregs. Lymphocyte antigen 75 , due to its ability to induce tolerance to autoantigens, is currently an intensively studied element of the potential treatment of autoimmune diseases $[2,5]$. Our results seem to support the hypothesis that $\mathrm{mDC}$ affect differentiation of Tregs and thus promote tolerance to own antigens in morphea.

Analysis of IL-17A expression in PBMC demonstrated its lowered values in morphea patients, as compared to the control group. Kurasawa et al. and Murata et al. observed higher serum concentration of IL-17A in SSc patients, but the results were not confirmed by Radstake et al. [6, 7]. Dańczak-Pazdrowska et al. detected higher expression of IL-17A in PBMC of patients of morphea accompanied by lower expression in lesional skin, as compared to healthy volunteers [21]. It is worth stressing that the patients included to this study presented a more severe, generalized type of disease, which might influence the results and explain the conflicting findings.

The course of treatment with UVA1 phototherapy did not significantly affect the expression of selected genes. However, higher expression of CLEC4C was noted in PBMC in patients with a more severe type of disease after UVA1 treatment. Moreover, a negative correlation was observed between LoSSI index and the expression of CLEC4C in PBMC of morphea patients after completing the treatment cycle. The mechanism of action of UVA1 is not fully understood, and the molecule which absorbs UVA1 remains unknown. It has been shown in some studies that ultraviolet radiation of various wavelengths may not only cause a decrease in the number of DCs but also influence maturation, migration, and interaction with Tregs. Another study revealed that effectiveness of UVA1 phototherapy in the treatment of morphea was associated with an increase in the number of CD34+ DCs in the dermis [22, 23]. The potential effects of UVA1 phototherapy on the number of Tregs in the skin and blood of morphea patients has not been the aim of studies yet. Application of extracorporeal photophoresis (ECP) in patients with SSc resulted in a decrease in peripheral Th17 count, with a decrease in skin thickness and an increase of Treg level [24]. Inhibition of the Th17/IL-23 pathway and induction of foxp3 Tregs in a psoriatic murine model, following application of photochemotherapy, was recently demonstrated [25]. However, a study of the mRNA of foxP3 in 5 atopic dermatitis patients treated with UVA1 did not reveal any significant changes in pre- and post-treatment biopsies. According to the authors, the clinical benefits of the UVA1 therapy are not related to activation of Tregs in atopic dermatitis [26]. Similarly, we did not observe any changes in expression of foxp3 Tregs or LY75 and CLEC4C in patients with morphea in the skin and blood before and after UVA1 treatment.

The results revealed a correlation between the expression of CLEC4C in PBMC and activity of the disease measured by LoSSI in the whole group of morphea patients. No correlations were documented between other analysed genes and LoSSI. However, higher expression of foxP3 was observed in the skin of patients with higher ANA titre. According to the literature, $47 \%$ to $76 \%$ of patients with morphea present ANA. In a study conducted on 50 patients with morphea ANA were detected in $18 \%$ of the patients in the titre of $1: 40$ to $1: 320$ [27]. The frequency of positive ANA in the studied group was higher as compared to literature data. This is probably due to the fact that the study group consisted of patients suffering from severe and disseminated forms of morphea (generalized and linear morphea) qualified for phototherapy treatment and more severe types of the disease present higher frequency of positive ANA. Skin samples were obtained from generalized and linear types of morphea. However, because of the low number of patients included in the study, the statistical analysis was conducted between the whole group of morphea patients vs. healthy volunteers, not between certain subtypes of morphea.

On the basis of the documented results we have not been able to confirm the involvement of analysed subsets of DC and Tregs in the mechanism of action of UVA1 phototherapy in the studied disease. The above-mentioned observation might result from the relatively small study group. Further research on protein level using immunohistochemistry to assess the presence of analysed subsets of DC directly in the skin are necessary. However, the results point to CLEC4C as a possible biomarker associated with the disease activity. Also IL-17A and TGF- $\beta$ seem to play an important role in determining the specific microenvironment promoting differentiation of Tregs.

In conclusion, it seems that our results provide just an introduction to studies on markers of DC and Tregs and their role in both the UVA1 mechanism and pathogenesis of morphea. Therefore further studies are necessary involving the assessment of certain markers of DC and Tregs in both the skin and blood of morphea patients at the 
protein product level using flow cytometry and/or immunohistochemistry.

\section{Conflict of interest}

The authors declare no conflict of interest.

\section{References}

1. Fett N. Scleroderma: nomenclature, etiology, pathogenesis, prognosis and treatments: Facts and controversies. Clin Dermatol 2013; 31: 432-7.

2. Shrimpton RE, Butler M, Morel AS, et al. CD205 (DEC-205): a recognition receptor for apoptotic and necrotic self. Mol Immunol 2009; 46: 1229-39.

3. Dzionek A, Sohma Y, Nagafune J, et al. BDCA-2, a novel plasmacytoid dendritic cell-specific type II C-type lectin, mediates antigen capture and is a potent inhibitor of interferon alpha/beta induction. J Exp Med 2001; 194: 1823-34.

4. Blanco P, Palucka AK, Pascual V. Dendritic cells and cytokines in human inflammatory and autoimmune diseases. Cytokine Growth Factor Rev 2008; 19: 41-52.

5. Gołąb J, Jakóbisiak M, Lasek W, Stokłosa T. Immunology. Wydawnictwo Naukowe PWN, Warsaw 2007; 376-95.

6. Kurasawa K, Hirose K, Sano H, et al. Increased interleukin-17 production in patients with systemic sclerosis. Arthritis Rheum 2000; 43: 2455-63.

7. Murata M, Fujimoto M, Matsushita T, et al. Clinical association of serum interleukin-17 levels in systemic sclerosis: is systemic sclerosis a Th17 disease? J Dermatol Sci 2008; 50: 240-2.

8. York NR, Jacobe HT. UVA1 phototherapy: a review of mechanism and therapeutic application. Int J Dermatol 2010; 49: 623-30.

9. Arkachaisri T, Vilaiyuk S, Torok KS, Medsger TA. Development and initial validation of the Localized Scleroderma Skin Damage Index and Physician Global Assessment of disease damage: a proof-of-concept study. Rheumatology 2010; 49: 373-81.

10. Gilmour TK, Wilkinson B, Biret SN, et al. Analysis of dendritic cell populations using a revised histological staging of morphea. Br J Dermatol 2000; 143: 1183-92.

11. Chomczynski P, Sacchi N. Single-step method of RNA isolation by acid guanidinium thiocyanate-phenol-chloroform extraction. Anal Biochem 1987; 162: 156-9.

12. Kowalczyk MJ, Dańczak-Pazdrowska A, Szramka-Pawlak B, Żaba R, Silny W, Osmola-Mańkowska A. Expression of selected human endogenous retroviral sequences in skin and peripheral blood mononuclear cells in morphea. Arch Med Sci 2012; 8: 819-25.

13. Pattyn F, Speleman F, De Paepe A, Vandesompele J. RTPrimerDB: the real-time PCR primer and probe database. Nucleic Acids Res 2003; 31: 122-3.

14. Wollenberg A, Wagner M, Günther S. Plasmacytoid dendritic cells: a new cutaneous dendritic cell subset with distinct role in inflammatory skin diseases. J Invest Dermatol 2002; 119: 1096-102.

15. Ghoreishi M, Kellet CV, Dutz JP. Type I IFN-induced protein MXA and plasmocytoid dendritic cells in lesions of morphea. Exp Dermatol 2012; 21: 417-9.

16. Cederblad B, Blomberg S, Vallin H, Perers A, Alm GV, Ronnblom L. Patients with systemic lupus erythematosus have reduced numbers of circulating natural interferon-alpha-producing cells. J Autoimmun 1998; 11: 465-70.
17. Farkas L, Beiske K, Lund-Johansen F, Brandtzaeg P, Jahnsen FL. Plasmacytoid dendritic cells (natural interferon-alpha/beta-producing cells) accumulate in cutaneous lupus erythematosus lesions. Am J Pathol 2001; 159: 237-43.

18. Antiga E, Quaglino P, Bellandi S, et al. Regulatory T cells in the skin lesions and blood of patients with systemic sclerosis and morphoea. Br J Dermatol 2010; 162: 1056-63.

19. Dańczak-Pazdrowska A, Kowalczyk MJ, Szramka-Pawlak B, et al. Transforming growth factor-beta1 in plaque morphea. Postep Dermatol Alergol 2013; 30: 337-42.

20. Klein S, Kretz CC, Ruland V, et al. Reduction of regulatory $T$ cells in skin lesions but not in peripheral blood of patients with systemic scleroderma. Ann Rheum Dis 2011; 70: 1475-81.

21. Dańczak-Pazdrowska A, Kowalczyk M, Szramka-Pawlak B, et al. Interleukin-17A and interleukin-23 in morphea. Arch Med Sci 2012; 8: 1089-95.

22. Duthie MS, Kimber I, Dearman RJ, Norval M. Differential effects of UVA1 and UVB radiation on Langerhans cell migration in mice. J Photochem Photobiol B 2000; 57: 123-31.

23. Camacho NR, Sanchez JE, Martin RF, Gonzalez JR, Sanchez JL. Medium-dose UVA1 phototherapy in localized scleroderma and its effect in CD34-positive dendritic cells. J Am Acad Dermatol 2001; 45: 697-9.

24. Papp G, Horvath IF, Barath S, et al. Immunomodulatory effects of extracorporeal photochemotherapy in systemic sclerosis. Clin Immunol 2012; 142: 150-9.

25. Singh TP, Schon MP, Wallbrecht K, et al. 8-methoxypsoralen plus ultraviolet $A$ therapy acts via inhibition of the IL-23/Th17 axis and induction of Foxp3+ regulatory T cells involving CTLA4 signaling in a psoriasis-like skin disorder. J Immunol 2010; 184: 7257-67.

26. Schnopp C, Rad R, Weidinger A, et al. Fox-P3-positive regulatory $T$ cells are present in the skin of generalized atopic eczema patients and are not particularly affected by medium-dose UVA1 therapy. Photodermatol Photoimmunol Photomed 2007; 23: 81-5.

27. Wojas-Pelc A, Wielowieyska-Szybinska D, Kieltyka A. Presence of the antinuclear antibodies and antibodies to Borrelia burgdorferi among patients with morphea en plaque, deep linear scleroderma and atrophoderma Pasini-Pierini. Przegl Lek 2002; 59: 898-902. 